\title{
FACIT-Dyspnea 10 Item Short Form
}

National Cancer Institute

\section{Source}

National Cancer Institute. FACIT-Dyspnea 10 Item Short Form. NCI Thesaurus. Code C121853.

A patient-reported outcome measure designed to evaluate an individual's shortness of breath across ten functional activities over the past 7 days. 